\title{
A Case Report on Ceftriaxone Induced Periorbital Edema
}

\author{
Binu Mathew ${ }^{1, *}$, Sunitt Thomas ${ }^{1}$, Shiv Kumar¹, Doddaya Hiremath', Rita Doggalli² \\ 1'Department of Pharmacy Practice, NET Pharmacy College, Raichur, Karnataka, INDIA. \\ ${ }^{2}$ Department of Obstetrics and Gynecology, Navodaya Medical College and Research Center, Raichur, Karnataka, INDIA.
}

\begin{abstract}
Ceftriaxone is a third generation cephalosporin antibiotic, used commonly due to their broad spectrum of activity. As the therapeutic use of cephalosporin are increasing, reports of hypersensitivity reactions are also on the rise. Allergic reactions to beta-lactamase antibiotics are the most common cause of adverse reactions mediated by specific immunological mechanism. A 25-year-old female Para 1, living 1 (P1, L1) with 39 weeks and 4 days of gestation was hospitalized in the Obstetrics and Gynecology department. On examination, contracted pelvis was present, so lower uterine segment caesarean section was done. A test dose of $0.1 \mathrm{ml}$ of ceftriaxone was given intradermal pre-operative, which was non-reactive. Later, injection ceftriaxone $1 \mathrm{~g}$ IV was given, following which she developed periorbital edema after $20 \mathrm{~min}$. Ceftriaxone was withdrawn. On examination, there was swelling and puffiness of eyelids and around the right eye. The patient was administered Inj. Avil 2 ml (Pheniramine Maleate) IV stat as treatment. Periorbital edema is a rare presentation of adverse drug reaction produced by ceftriaxone.
\end{abstract}

Key words: Adverse drug reactions, Anaphylaxis, Ceftriaxone, Hypersensitivity reactions, Naranjo scale, Periorbital edema.

\section{INTRODUCTION}

Ceftriaxone is a broad spectrum, third generation cephalosporin antibiotic commonly used for the treatment of wide range of serious infections like bacterial meningitis, multidrug resistant typhoid, urinary tract infection, septicaemia. ${ }^{1}$ Drug induced allergic reactions can be grouped into $\operatorname{IgE}$ mediated and non- $\operatorname{IgE}$ mediated. $\mathrm{IgE}$ mediated reactions include angioedema, urticardia, anaphylaxis and bronchospasm which occurs within $72 \mathrm{hr}$ of exposure to the drug. Non-IgE mediated reactions are characterized by interstitial nephritis, Steven Johnson syndrome, serum sickness, haemolytic leukemia. ${ }^{2}$ The incidence of ceftriaxone induced hypersensitivity reaction is $1-3 \%$, however the incidence of anaphylaxis accounts to $0.1-0.0001 \%$ only. ${ }^{3,4}$ There were previous case reports of hypersensitivity and the presentation is mostly anaphylactic or rashes. ${ }^{5}$ Here, we present a case of ceftriaxone - induced periorbital edema which is a rare presentation.

\section{CASE REPORT}

A 25-year-old female para 1, living 1 (P1, L1) with 39 weeks and 4 days of gestation was hospitalized in the Obstetrics and Gynaecology department of Navodaya Medical College Hospital and Research Centre, Raichur, Karnataka.. On examination, contracted pelvis was present, so lower uterine segment caesarean section was done. A test dose of $0.1 \mathrm{ml}$ of ceftriaxone was given intradermal pre-operative, which was non-reactive. Later, injection ceftriaxone 1 $\mathrm{g} I V$ was given at $8.30 \mathrm{am}$, following which she developed periorbital edema after $20 \mathrm{~min}$. Ceftriaxone was withdrawn. On examination, there was swelling and puffiness of eyelids and around the right eye as shown in the Figure 1. Her vitals were BP: $114 / 76 \mathrm{mmHg}$, PR: 86 bpm, Temp: Afebrile and RR: $16 \mathrm{cpm}$. There was no local rise of temperature, no skin colour change and no tenderness and the edema was only around right eye. It was diagnosed as susceptible adverse drug reaction with ceftriaxone and requested to Pharmacovigilance Committee, Department
DOI: 10.5530/ijopp.14.3.45

Address for correspondence: Mr. Binu Mathew Assistant Professor, Department of Pharmacy Practice, N.E.T. Pharmacy College, Mantralayam Road, Raichur-584103, Karnataka, INDIA.

Phone no: +91 8971698943 Email Id: binum2@gmail.com

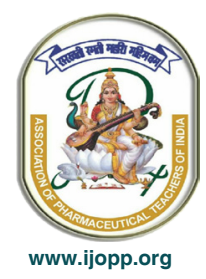




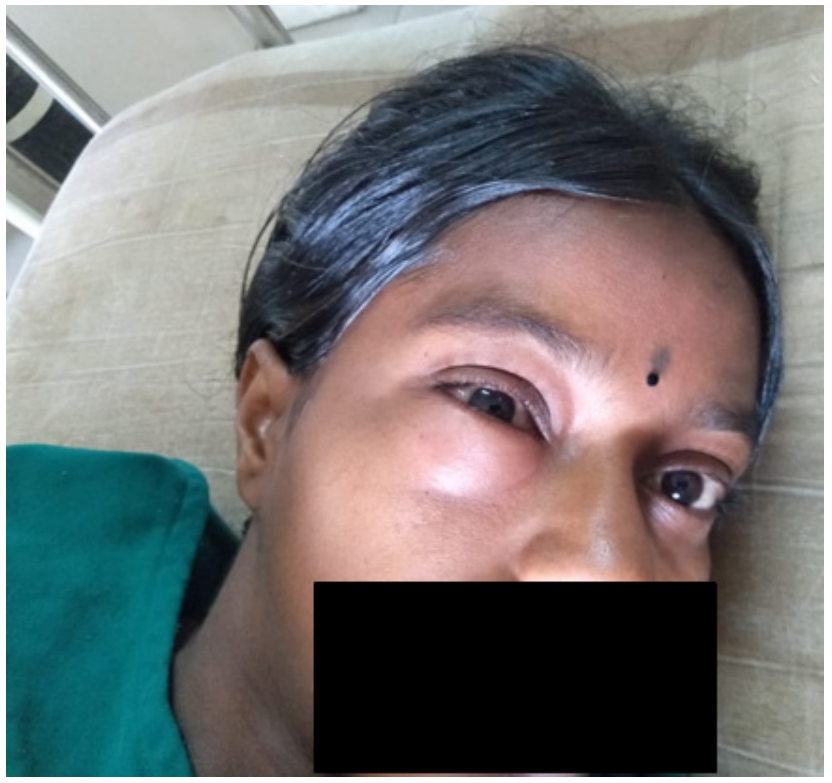

Figure 1: Ceftriaxone induced periorbital edema.

of Pharmacy Practice for further reference; mean while patient was administered Inj. Avil $2 \mathrm{ml}$ (Pheniramine Maleate) IV stat as treatment. There was no personal history of atopy or allergy to any other substances. Complete blood count and thyroid test values were within normal limits throughout her pregnancy and also postpartum. Then patient got recovered from adverse drug reaction and was asked for follow-up after one week. Her concomitant medications included Pantoprazole $40 \mathrm{mg}$, Metoclopramide 5mg, Ondansetrone $4 \mathrm{mg}$ and injection Tranexamic acid 500mg in $100 \mathrm{ml}$ normal saline The Pharmacovigilance Committee members critically analysed the case, evaluated sufficient evidences and suggested as ceftriaxone induced periorbital edema. The consent form from the patient was taken for the publication of the data as a case report.

\section{Causality assessment}

To evaluate the relationship between the drug and reaction, we have performed causality assessment by using Naranjo scale and obtained a score of 06 showing probable ADR. ${ }^{6}$

\section{DISCUSSION}

Cephalosporin's have a four membered beta lactam ring, whose structure varies from substitution at the R1 and R2 side chains. Cefotaxime, ceftriaxone, cefepime and cefuroxime have a R1 side chain and the hypersensitivity reactions with the above mentioned drugs are due to the presence of this side chains. ${ }^{7}$ Ceftriaxone is used commonly in adult patient and children for serious infections. It selectively and irreversibly inhibits bacterial cell wall synthesis by binding to penicillinbinding proteins that catalyze the cross-linking of the peptidoglycan polymers forming the bacterial cell wall. Hypersensitivity reactions due to ceftriaxone therapy are potentially serious. ${ }^{8,9}$

In this case ceftriaxone was given initially as a test dose preoperatively for chemoprophylaxis. When the test dose was given, there was no allergic reaction. However, later, when the entire dose was given, the patient developed periorbital edema around right eye, which is an unusual presentation of the adverse reaction due to ceftriaxone. Earlier cases of hypersensitivity type-1 with ceftriaxone were reported with maculopapular rashes, urticarial and angioedema which is an $\operatorname{IgE}$-mediated allergy. The possible mechanism is thought to be development of $\mathrm{IgE}$ antibodies against antigenic determinants that are unique to beta-lactams. ${ }^{5}$ Unlike penicillin's, skin testing for cephalosporin's is not heterogeneous. And there is no skin test that can constantly expect whether a patient will notice an allergic reaction to ceftriaxone. ${ }^{10}$ Routine skin testing with a cephalosporin before its administration is not useful for predicting immediate hypersensitivity because of the extremely low sensitivity and PPV of the skin test. ${ }^{11}$

\section{CONCLUSION}

The periorbital edema in our patient was probably induced by ceftriaxone as validated using Naranjo probability scale with a score of 06 . Although the periorbital edema is a rare adverse effect of ceftriaxone and other cephalosporin's, clinicians should be aware of the possibility of such an occurrence and should be well known about the treatments to resolve the problems if an adverse reaction occurs. In this case the patient was recovered from the periorbital edema by immediately administering Injection Pheniramine Maleate. Further the patient was followed up for her condition and was found to be recovered; also she was advised to inform the clinicians about the reaction prior to future treatments.

\section{ACKNOWLEDGEMENT}

We express our sincere thanks to Director, Medical Superintendent, members of Pharmacovigilance Centre of Navodaya Medical College Hospital and Research Centre, Raichur and all the physicians, nursing staff of department of Obstetrics and Gynecology, NMCH and $\mathrm{RC}$, Raichur, for their valuable help and assistance to carry out this report. 


\section{CONFLICT OF INTEREST}

The authors declare no conflict of interest.

\section{ABBREVIATIONS}

IgE: Immunoglobulin E; Inj.: Injection; IV: Intravenous; PPV: Positive predictable value.

\section{SUMMARY}

Ceftriaxone can cause hypersensitivity type- 1 reaction, which is an $\mathrm{IgE}$-mediated allergy. The possible mechanism is thought to be development of $\operatorname{IgE}$ antibodies against antigenic determinants that are unique to beta lactams. Thus higher doses of these drugs may cause periorbital edema.

\section{REFERENCES}

1. Hirachan R, Gopi PH, Bibek R, et al. Anaphylaxis to Ceftriaxone - Evaluation of Two Cases. Journal of Gandaki Medical College-Nepal. 2018;11(2):82-4.
2. Devuni V. Urticaria due to Ceftriaxone: A Case Report. IJRR. 2019;6(6):215-7.

3. Kelkar PS, Li JT. Cephalosporin allergy. New Eng J Me. 2001;345(11):804-9.

4. Ernst MR, van Dijken PJ, Kabel PJ, Draaisma JM. Anaphylaxis after first exposure to ceftriaxone. Acta Paediatr. 2002;91(3):355-6.

5. Anuhya V, Nayak V, Somu K, Thomson SR, Sujatha BS. Ceftriaxone - induced periorbital edema. Asian J Pharm Clin Res. 2019;12(1):7-8.

6. Narano CA, Busto U, Sellers EM et al. A method for estimating the probability of adverse drug reactions. Clin Pharmacol Ther. 1981;30(2):239-45.

7. Thomson SR, Ommurugan B, Patil N. Ceftriaxone induced hypersensitivity reactions following intradermal skin test: Case series. J Clin Diagn. 2017;11(10):1-4

8. Petri WA. Penicillins, cephalosporins and other beta lactam antibiotics. Goodman and Gilman's The Pharmacological Basis of Therapeutics $12^{\text {th }} \mathrm{Ed}$ McGraw-Hill, New York. 2011;1505-20.

9. Russelian A, Chandrasekaran V, Nanda C, Palaniswamy S. Hypersensitivity due to ceftriaxone mimicking measles in a child. Ind J Pharmacol. 2013;45(5):528-9.

10. Novalbos A, Sastre J, Cuesta J, et al. Lack of allergic cross reactivity to cephalosporin among patients allergic to penicillins.Clin Ex Allerg. 2001;31(3):438-43.

11. Yoon SY, Park SY, Kim S, et al. Validation of the cephalosporin intradermal skin test for predicting immediate hypersensitivity: A prospective study with drug challenge. Allergy. 2013;68(7):938-44. 